\title{
Electrothermal Modeling of IGBT's: Application to Short-Circuit Conditions
}

\author{
Anis Ammous, Kaiçar Ammous, Hervé Morel, Bruno Allard, Member, IEEE, Dominique Bergogne, Fayçal Sellami, \\ and Jean Pierre Chante, Member, IEEE
}

\begin{abstract}
This paper discusses the possible estimation of IGBT failure phenomena by mean of simulation. The studied destruction mode addresses the large surges, especially the short-circuit of IGBT's. In this case the reason of the device destruction is a thermal runaway. Thus we have developed an electrothermal model of the IGBT. The developed model may be implemented in any circuit simulators featuring a high level description language (SABER, ELDO, SMASH, PACTE. . .). The used electrical model is based on the Hefner model of the IGBT. A bidimensional finite element thermal model is considered. This model has been optimized to gives a good trade-off between accuracy and simulation cost. To validate the implemented model, finite element simulations have been performed with the ATLAS two-dimensional (2-D) numerical simulator. The study is completed with the comparison between experimental and simulation results. It is shown that the proposed electrothermal model allows the prediction of the IGBT destruction phases in the case of large surges. So, users of IGBT components have the possibility to estimate, by mean of simulation, the possible failure (due to large surges) of these devices in the case of complex converters. This enables the possibility for developing protection systems for IGBT's without any destructive test.
\end{abstract}

Index Terms-Electrothermal modeling, failure, IGBT, numerical simulation, short-circuit.

\section{NOMENCLATURE}

$A\left(\mathrm{~cm}^{2}\right)$, Effective area and length of the semiconductor de-

$L_{0}(\mathrm{~cm})$ vice.

c Silicon specific heat $(\mathrm{J} / \mathrm{g} / \mathrm{K})$.

$C_{\mathrm{bc} j} \quad$ Base-collector depletion capacitance (F).

$C_{\mathrm{ce}} \quad$ Collector-emitter redistribution capacitance $(\mathrm{F})$.

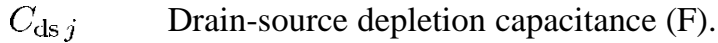

$C_{\mathrm{gd}} \quad$ Gate-drain capacitance $(\mathrm{F})$.

$C_{\mathrm{gd} j} \quad$ Gate-drain overlap depletion capacitance (F).

$C_{\mathrm{gs}} \quad$ Gate-source capacitance (F).

$C_{\text {oxd }} \quad$ Oxide capacitance per unit area $\left(\mathrm{F} / \mathrm{cm}^{2}\right)$.

$C_{\text {ox }} \quad$ Gate-drain overlap oxide capacitance (F).

$D \quad$ Ambipolar diffusivity $\left(\mathrm{cm}^{2} / \mathrm{s}\right)$.

$D_{c} \quad$ Carrier-carrier scattering diffusivity $\left(\mathrm{cm}^{2} / \mathrm{s}\right)$.

$I_{A}, I_{T} \quad$ Anode current (A).

$I_{b \mathrm{ss}} \quad$ Charge control base current (A).

$I_{c \text { ss }} \quad$ Charge control collector current (A).

Manuscript received January 25, 1999; revised March 21, 2000. Recommended by Associate Editor, W. M. Portnoy.

A. Ammous and F. Sellami are with the Power Electronic Laboratory (LEP), Ecole Nationale d'Ingénieurs de Sfax (ENIS), Sfax, Tunisia.

K. Ammous, H. Morel, B. Allard, D. Bergogne, and J. P. Chante are with the Centre de Génie Electrique de Lyon (CEGELY), UMR 5005 CNRS, Institut National des Sciences Appliqués (INSA) de Lyon, Villeurbanne F-69621, France. Publisher Item Identifier S 0885-8993(00)05574-5.
$I_{\text {gen }}$

$I_{\mathrm{MOS}}$

$I_{\text {mult }}$

$K$

$k$

$K_{p \operatorname{lin}}$

$K_{p \text { sat }}$

$L$

$n$

$n_{\mathrm{eff}}$

$N_{A}$

$N_{L}$

$N_{\mathrm{sc} l}$

$N_{\text {sat }}$

$n_{i}$

$p$

$\Delta p$

$P_{L 0}$

$P_{H 0}$

$P_{\text {in }}(t)$

$q$

$Q_{T}$

$Q_{H}$

$Q_{L}$

$R_{b}$

$T$

$T_{\text {in }}$

$U_{T}$

$V_{A K}, V_{\text {AC }}$

$V_{\text {eb }}$

$V_{\text {ebd }}$

$V_{\mathrm{bc}}$

$V_{\text {Bcbo }}$

$V_{\text {dg }}$

$V_{\text {GS }}$

$V_{\mathrm{FB}}$

$W$

$W_{L}$

$W_{\mathrm{bc} j}$

$W_{\mathrm{ds} j}$

$W_{\operatorname{gd} j}$

$W_{H}$
Thermally generated leakage current (A).

Mosfet current (A).

Multiplication current (A). Thermal conductivity $(\mathrm{W} / \mathrm{cm} / \mathrm{K})$. Boltzmann constant $\left(\mathrm{J} / \mathrm{cm}^{2} / \mathrm{K}\right)$.

Linear region MOSFET transconductance parameter $\left(\mathrm{A} / \mathrm{V}^{2}\right)$.

Saturation region MOSFET transconductance parameter $\left(\mathrm{A} / \mathrm{V}^{2}\right)$.

Ambipolar diffusion length $(\mathrm{cm})$.

Electron concentration $\left(\mathrm{cm}^{-3}\right)$.

Effective LDB (Low Doped Base) doping level concentration $\left(\mathrm{cm}^{-3}\right)$.

Acceptor impurity level concentration (in the $P / P^{+}$ body) $\left(\mathrm{cm}^{-3}\right)$.

Doping level concentration in the base $\left(\mathrm{cm}^{-3}\right)$.

Collector-base space charge concentration $\left(\mathrm{cm}^{-3}\right)$.

Velocity saturation component of $N_{\mathrm{scl}}\left(\mathrm{cm}^{-3}\right)$.

Intrinsic carrier concentration $\left(\mathrm{cm}^{-3}\right)$.

Hole concentration $\left(\mathrm{cm}^{-3}\right)$.

Excess carrier concentration $\left(\mathrm{cm}^{-3}\right)$.

$\Delta p$ at HDB (Highly Doped Base) edge of the LDB $\left(\mathrm{cm}^{-3}\right)$.

$\Delta p$ at emitter edge of the HDB $\left(\mathrm{cm}^{-3}\right)$.

Input dissipated power (W).

Electron charge (C).

Total excess carrier base charge (C).

Excess carrier charge in the HDB (C).

Excess carrier charge in the LDB (C).

Conductivity-modulated base resistance (Ohm).

Absolute temperature (K).

Input temperature $(\mathrm{K})$.

Thermodynamic voltage (V).

Anode-cathode voltage (V).

Emitter-base voltage (V).

Emitter-base diffusion voltage (V).

Base-collector voltage (V).

Base-collector breakdown voltage $(\mathrm{V})$.

Drain-gate voltage $(\mathrm{V})$.

Gate-source voltage (V).

Flat band voltage (V).

Quasineutral LDB width (cm).

Metallurgical LDB width (cm).

Base-collector depletion width $(\mathrm{cm})$.

Drain-source depletion width $(\mathrm{cm})$.

Gate-drain overlap depletion width $(\mathrm{cm})$.

Metallurgical width of HDB $(\mathrm{cm})$. 
$W_{\text {eff }} \quad$ Effective width for base transport $(\mathrm{cm})$.

$W_{m} \quad$ Corresponding $W_{\mathrm{bc} j}$ (when breakdown occurs) for NPT (Non Punch-Trough) structure (cm).

$\rho \quad$ Silicon mass density $\left(\mathrm{g} / \mathrm{cm}^{3}\right)$.

$\mu_{n}, \mu_{p} \quad$ Electron, hole mobilities in the base $\left(\mathrm{cm}^{2} / \mathrm{V} / \mathrm{s}\right)$.

$\mu_{n c}, \mu_{p c} \quad$ Carrier-carrier scattering mobilities $\left(\mathrm{cm}^{2} / \mathrm{V} / \mathrm{s}\right)$.

$\beta_{\text {PNP }} \quad$ Current gain of internal PNP bipolar transistor inside the IGBT.

$\psi_{B} \quad$ Substrate Fermi potential (V).

$\varepsilon_{S} \quad$ Silicon permittivity $(\mathrm{F} / \mathrm{cm})$.

$\tau_{\mathrm{HL}} \quad$ High-level injection lifetime in the base (s).

$\tau_{L} \quad$ High-level injection lifetime in LDB (s).

$\tau_{e} \quad$ Effective lifetime in depletion region (s).

$\theta \quad$ Transverse field transconductance factor $\left(\mathrm{V}^{-1}\right)$.

\section{INTRODUCTION}

$\mathbf{T}$ HE main component of the heat generation inside a semiconductor device is equal to the scalar product of the electric field by the current density. The heat generation becomes more critical in the case of large surges specially in short-circuit conditions.

Literature shows some studies about the electrothermal modeling of the IGBT to evaluate the effect of the device self-heating on the electrical characteristics [1]-[6]. In these studies the thermal model is a classical unidimentionnal model based on the finite difference method (with a little number of nodes) which is not adapted to the case of IGBT large surges operation [7]. Indeed to avoid a large error on the estimation of the device temperature in the case of a large surge, a high number of nodes is required. Moreover, in these studies electrothermal modeling is performed by evaluating physical parameters as functions of unique junction temperature. Really, the evaluation of the electrical parameters as functions of temperature depends on the local region where the corresponding physical phenomenon takes place. Specially, in the case of large surges, the temperature gradient inside the IGBT is high and the temperature distribution is bidimentionnal at least [8]-[10]. So, many internal temperatures in the device should be taken into account in the electrical model.

The present paper covers a study about the estimation of IGBT failure phenomena, by mean of simulation. An electrothermal model of the IGBT is then developed. The model has been implemented in the circuit simulator PACTE [11]. We note that it is possible to implement the proposed model in any other circuit simulator featuring a high-level description language like SABER [12], ELDO [13] or SMASH [14].... Section II covers the presentation of the electrical model of the IGBT, based on the A. Hefner model [15], [16]. This model, based on semiconductor device equations, gives a good description of the IGBT electrical behavior. A bidimensional thermal model is proposed in Section III. This model is a thermal network based on the finite element method.

To justify the geometrical description of the thermal model, a one half of a symmetric IGBT cell is investigated using the general-purpose numerical device simulator ATLAS two-dimensional (2-D) [17].

Finally, physical parameters have been evaluated using the different local temperature throughout the device (Section IV). Comparisons between numerical simulations, experimental

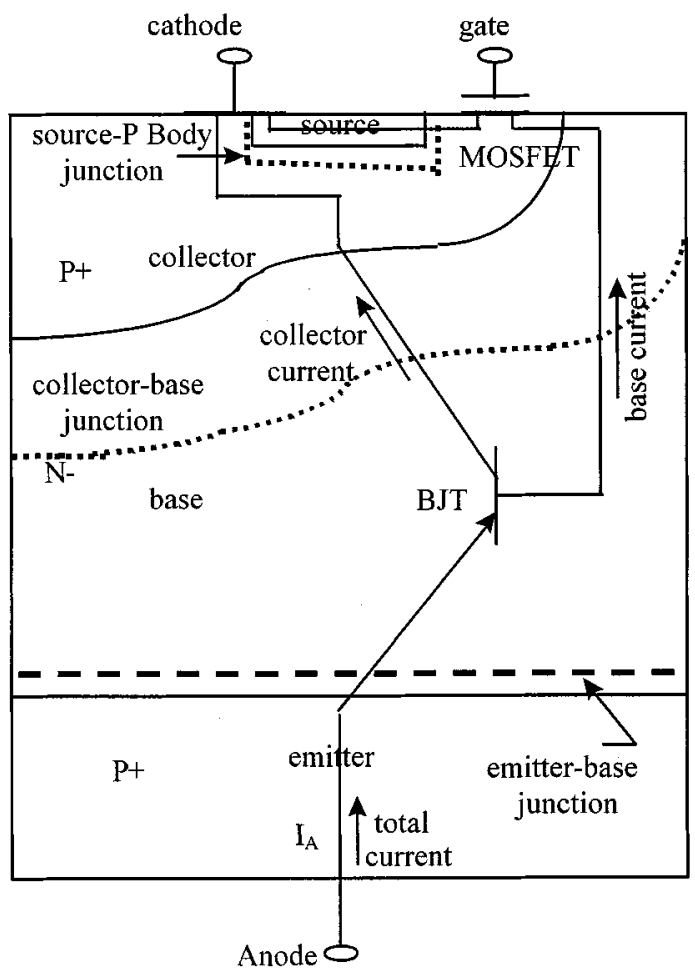

Fig. 1. Schematic one-half of symmetric IGBT cell and its simplified equivalent electrical circuit used to develop the electrical model.

results and their equivalent electrothermal circuit simulations show that the estimation of the IGBT failure, in the case of large surges, is possible by mean of simulation.

\section{EleCtricAl Modeling}

The electrical model of the power insulated gate bipolar transistor by Hefner [15], [16] has been used. This model gives a good description of the IGBT behavior specially in the case of steady-state and quasi-static operating conditions. The model is based on the equivalent circuit of a MOSFET which supply the base current to a NPN bipolar transistor [18]. The schematic of half of a symmetric IGBT cell with the basic principles of the circuit model are shown in Fig. 1. When the emitter-base junction is forward biased, holes are injected into the epitaxial layer $\left(N^{-}\right)$from the substrate $\left(P^{+}\right)$. The hole concentration injected in the base (at the emitter-base junction limit) is given by the classical relation

$$
p=p_{0} \exp \left(\frac{V_{\mathrm{eb}}}{U_{T}}\right)
$$

where $p_{0}$ is the hole concentration in the base at the thermodynamic equilibrium.

Since the epitaxial layer is much less doped than the substrate, then this yields the high-level injection of holes in the base $(p \approx$ $n$ ). If the total current density $\left(I_{T}\right)$ is assumed to be uniform in the base, the ambipolar diffusion equation is given by [15], [16]

$$
\frac{\partial^{2} p}{\partial x^{2}}=\frac{p}{L^{2}}+\frac{1}{D} \frac{\partial p}{\partial t}
$$

with $L=\sqrt{\tau_{\mathrm{HL}} D}$. 


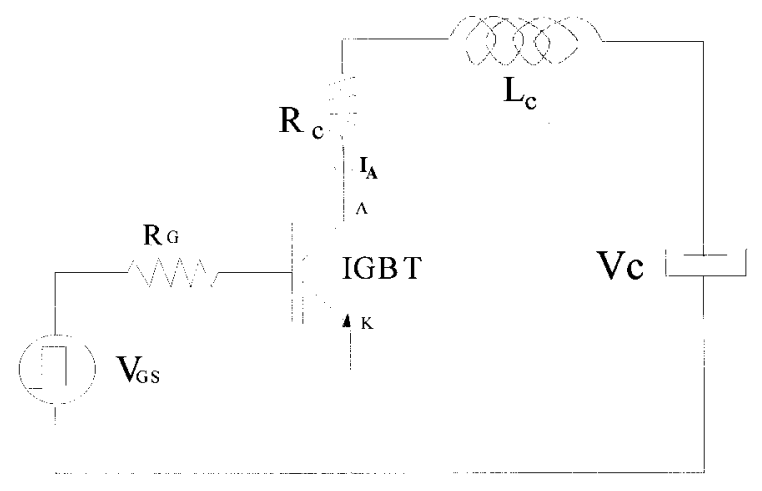

Fig. 2. Experimental and simulated circuit used to perform dynamic and static characteristics of the studied IGBT's.

The IGBT electrical model takes into account the carrier multiplication and thermal generation phenomena within the base-collector depletion region. Indeed, the carrier multiplication phenomenon is characterized by the multiplication factor $M$ approximated by the following empirical expression [18].

$$
M=\frac{1}{1-\left(\frac{V_{\mathrm{L} c}}{f V_{\mathrm{Bcb} 0}}\right)^{n}}
$$

The parameters $n$ and $f$ depend mainly on the doping level $N_{L}$, and the breakdown voltage, $V_{\mathrm{Bcb} 0}$.

The thermally generated leakage current is given by [19]

$$
I_{\text {gen }}=\frac{q A n_{i}(T)}{\tau_{e}} W_{\mathrm{bc} j}
$$

where $W_{\mathrm{bc} j}$ is the base-collector depletion width.

Further details about the IGBT analytical model may be found in [15], [16] and [20]-[23]. The expressions used to describe the PT IGBT model have been listed in Appendix 1.

The electrical circuit used in simulation and experiment is shown in Fig. 2. The experimental and simulation results, obtained for two devices and their corresponding electrical models, are given in Figs. 3-5. The model parameters for the two devices have been obtained with an identification procedure based on the fitting of experimental static and dynamic characteristics [24].

Fig. 3 shows the current-voltage (I-V) characteristic of the IRGBC $20 \mathrm{U}(13 \mathrm{~A} / 600 \mathrm{~V})$ for different gate-to-source voltage values for isothermal conditions $(T=300 \mathrm{~K})$. Figs. 4 and 5 gives the transient switching characteristics for isothermal conditions $(T=300 \mathrm{~K})$ of the IRGBC $20 \mathrm{U}$ and the BUP 202 $(15 \mathrm{~A} / 1000 \mathrm{~V})$ devices, respectively. The different waveforms $V_{\mathrm{GS}}, I_{A}$ and $V_{\mathrm{AC}}$ show the good agreement between experimental and simulation results. So, that confirms that the electrical model, developed by Hefner, covers a large physical description of the different phenomena inside the IGBT. Then it may be used in the developed electrothermal model.

All the electrical model parameters corresponding to the IRGBC 20U and the BUP 202 devices are given in Appendix 2.

\section{THERMAL MODELING}

\section{A. State of the Art}

Because most of the semiconductor device models are implemented in circuit simulators, thermal circuit networks are the

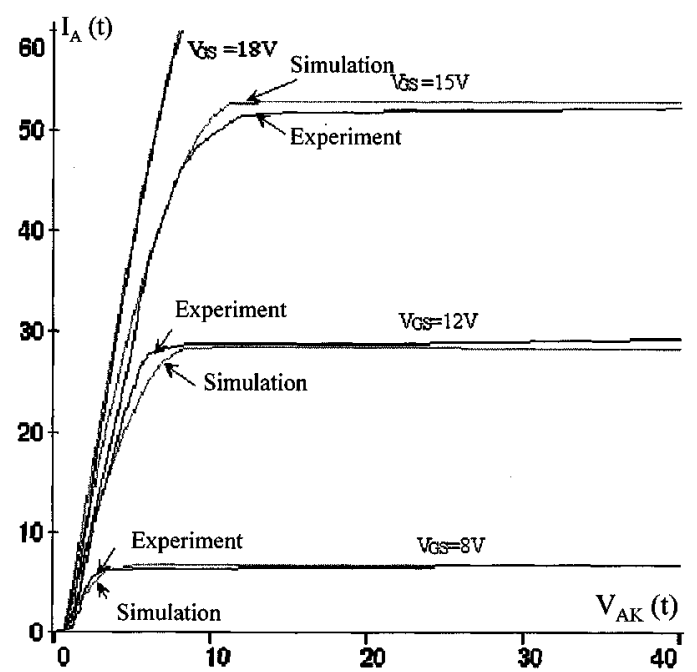

Fig. 3. Experimental and simulation static characteristic of the IRGBC 20U obtained for different gate-to-source voltage values.

practical models for electrothermal simulations. Literature proposes some approaches to construct thermal networks equivalent to a discretization of the heat equation. For example the finite difference method (FDM) [3]-[25] and the finite element method (FEM) [7]-[26] are proposed.

In the case of vertical power devices, where the thickness $L_{0}$ is small compared to other dimensions, it is commonly considered that heat is generated at the top surface of silicon and flows uniformly along the $x$-axis (perpendicular to the silicon surface). So, the top surface is considered to be a geometrical boundary of the device at $x=0$, where the input power $P_{\mathrm{in}}(t)$ is assumed to be uniformly dissipated. The lower surface (at $\left.x=L_{0}\right)$ is considered to be the cooling boundary, where the temperature is assumed to be equal to the input temperature $T_{\text {in }}$ (Fig. 6). Convection and radiation are assumed to be negligible. So a one-dimensional (1-D) heat-flow may be considered

$$
\frac{\partial}{\partial x}\left[K(T) \frac{\partial T}{\partial x}(t, x)\right]=\rho c \frac{\partial T}{\partial t}(t, x)
$$

with boundary conditions

$$
\begin{aligned}
& \left.A K \frac{\partial T}{\partial x}\right]_{x=0}=-P_{\text {in }}(t) \\
& T\left(t, x=L_{0}\right)=T_{\text {in }}(t)
\end{aligned}
$$

The thermal conductivity is assumed to be equal to [3]

$$
K(T)=1.5486\left(\frac{300 \mathrm{~K}}{T}\right)^{4 / 3}
$$

Studies in [7] have shown the advantage of the finite element method compared to the difference element method specially in the case of large surges of short time duration, which is the case of IGBT short-circuit conditions.

So we retain thermal circuit networks based on the finite element method.

\section{B. Electrothermal Simulation of the IGBT With Numerical Simulations}

This section presents the IGBT electrothermal behavior in the case of short-circuit conditions. This study is performed with 

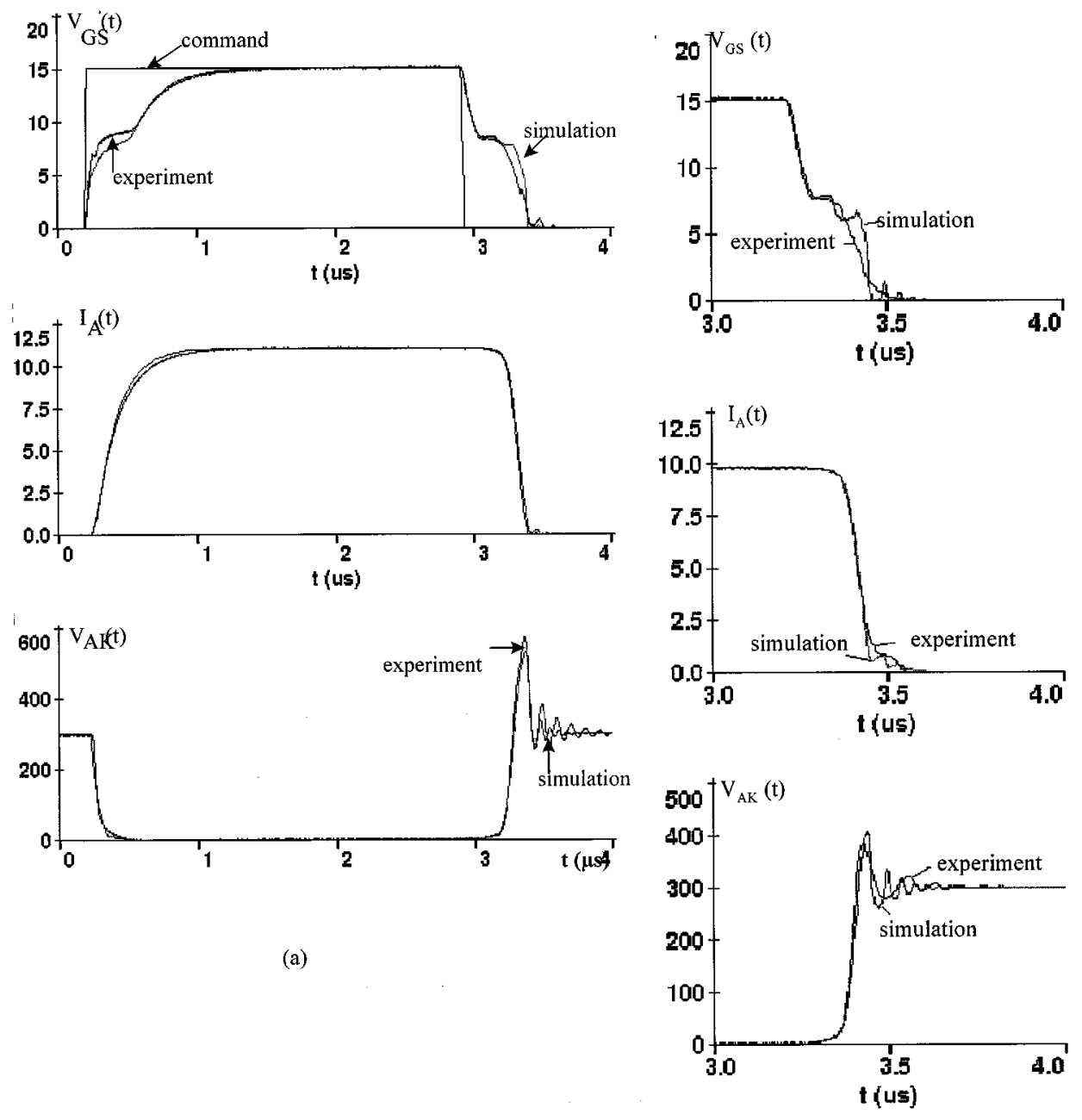

(b)

Fig. 4. Current and voltage waveforms obtained with the analytical model implemented in the PACTE simulator for the device IRGBC 20U inside the circuit in Fig. 2. (a) $R_{c}=27 \Omega, L_{c}=3.85 \mu \mathrm{H}, V_{c}=300 \mathrm{~V}$ and $R_{G}=271.5 \Omega$ (b) $R_{c}=30.4 \Omega, L_{c}=1.1 \mu \mathrm{H}, V_{c}=300 \mathrm{~V}$ and $R_{G}=119 \Omega$.

the ATLAS 2-D numerical device simulator [17]. This bidimensional study takes into account the coupled transport of heat and charge carriers which is based on the self consistent solution of Poisson's equation, the continuity equation for electrons and holes and the heat flow equation in space and time.

Half of a symmetric IGBT cell is investigated (Fig. 7). Collector-to-Emitter voltage is fixed at $400 \mathrm{~V}$, and $16 \mathrm{~V}$ is applied between gate and emitter. The device temperature distribution obtained by simulation is pictured in Fig. 8 after $13 \mu \mathrm{s}$ of short-circuit conditions.

As a thermal boundary condition for the simulation, a heat sink held at $300 \mathrm{~K}$ is attached to the bottom of the device.

Fig. 8 shows that the highest temperature reached in the IGBT half-cell is located at the end of the channel and near the intercellular region. The temperature distribution is bidimentionnal down to $20 \mu \mathrm{m}$ from the top of the cell and the temperature may be considered as unidimentionnal in the rest of the structure. These observations are important to build an economic thermal model. However, a 1-D thermal model is not sufficient to predict thermal runaway of the IGBT under large surges, because the power is not uniformly dissipated at the top of the device. The major part of power is dissipated at the end of the channel. This power results from a high electric field and high current density in this region. In the case of $n$-channel IGBT's the major part of the total current in the device crosses the channel. It is an electron current (the gain $\beta_{\mathrm{PNP}}$ of the internal PNP transistor is low). The latter analysis enables to construct a substantial thermal model adapted to the large surge conditions.

\section{IGBT Thermal Model}

As mentioned here-above, the proposed thermal model of the IGBT, should suit well with circuit simulators and should enable to predict the IGBT temperatures in the case of large power surges. So, a bidimensional thermal networks equivalent to a discretization of the heat equation by the finite element method is developed.

Studies in [7] and [26] show that the 1-D equivalent thermal network obtained by the finite element method may be represented by the circuit in Fig. 9. 

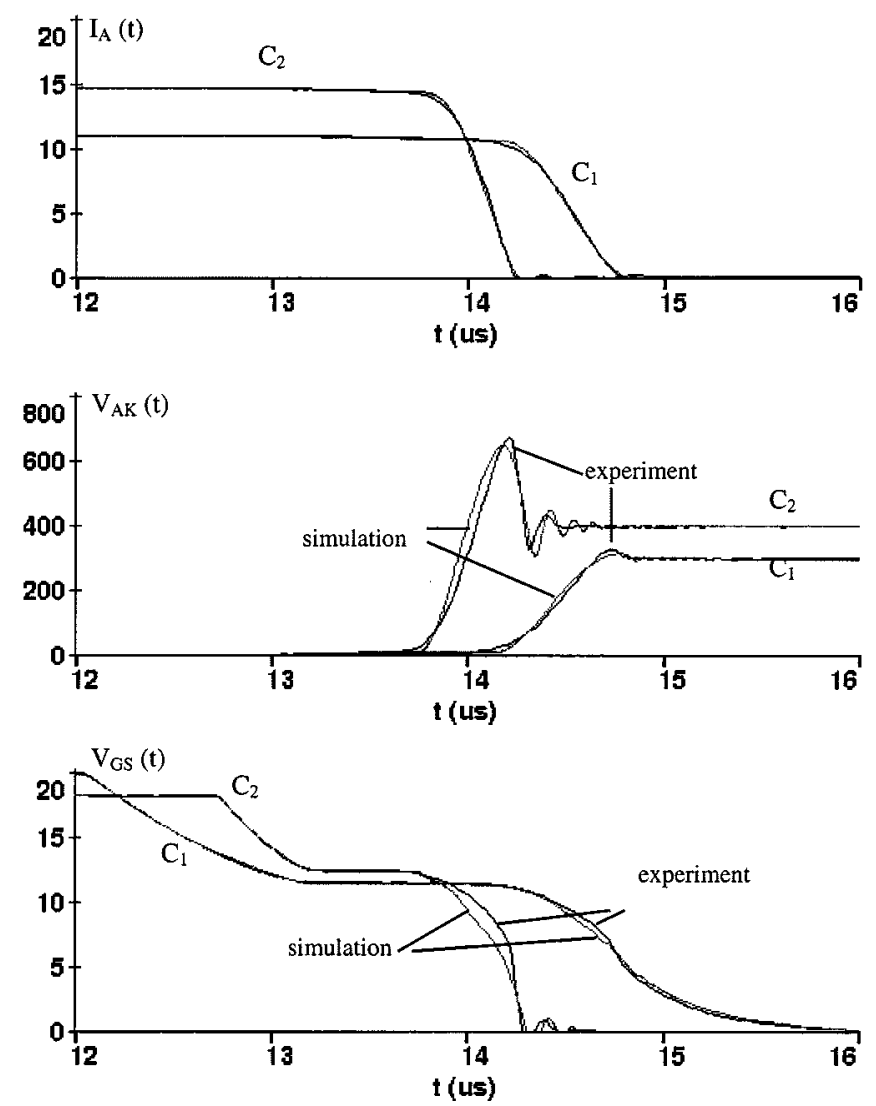

Fig. 5. Current and voltage waveforms obtained with the analytical model implemented in the PACTE simulator for the device BUP 202 inside the circuit in Fig. 2. (C1) $R_{c}=26.8 \Omega, L_{c}=2.6 \mu \mathrm{H}, V_{c}=300 \mathrm{~V}$ and $R_{G}=673.5 \Omega$ (C2) $R_{c}=27 \Omega, L_{c}=7.5 \mu \mathrm{H}, V_{c}=400 \mathrm{~V}$ and $R_{G}=387 \Omega$.

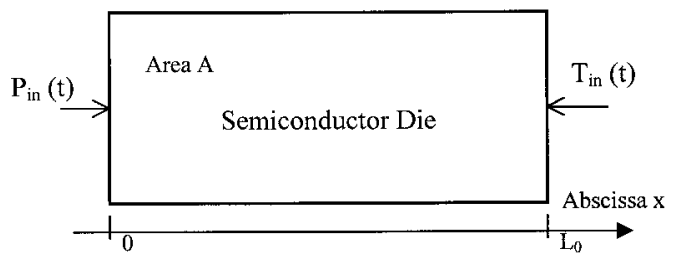

Fig. 6. Unidimensional semiconductor die representation considered for the thermal modeling.

Where

$$
C_{1}=\frac{\rho c A h}{2}, \quad C_{2}=-\frac{\rho c A h}{6} \quad \text { and } \quad R_{1}=\frac{h}{K A} .
$$

And $h$ is the discretization step.

This model is obtained by a choice of linear piecewise functions equal to 1 at node number $i$ and zero at any other node.

In the case of a bidimensional problem, a representation of the 2-D elements is the 2-D equivalent thermal network made of Lagrange-type triangular elements (Fig. 10) [7]-[26].

Where

$$
\begin{aligned}
C_{i i} & =\frac{\rho c A A_{e}}{3}, \quad C_{i j}=-\frac{\rho c A A_{e}}{12} \quad \text { and } \\
R_{i j} & =-\frac{4 A_{e}}{K A\left(\beta_{i} \beta_{j}+\gamma_{i} \gamma_{j}\right)} \quad 1 \leq i \leq j \leq 3 \\
\beta_{i} & =\left(y_{i}-y_{k}\right) \\
\gamma_{i} & =\left(x_{k}-x_{j}\right)
\end{aligned}
$$

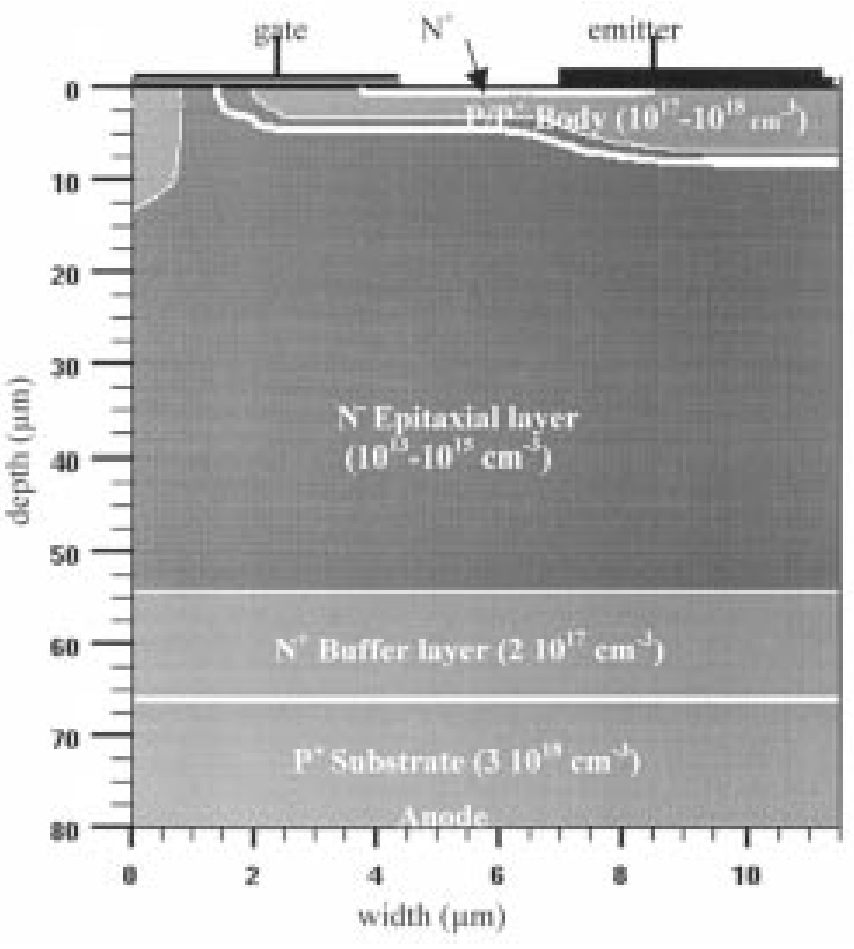

Fig. 7. Half of a symmetric IGBT cell structure used in the numerical simulator (ATLAS 2-D).

where $x_{i}, y_{i}$ are the coordinate of the node number $i$ in the $(x, y)$ axes and $i, j, k$ are a circular permutation of the nodes 1,2 and 3 which compose the triangular element surface $A_{e}$. The 1-D and 2-D latter models may be used to represent the thermal phenomena inside the IGBT. Indeed the complete thermal model is shown in Fig. 11. This model is a combination of a 1-D and a 2-D equivalent thermal network. It enables the optimization of the simulation cost. In some ten of micrometers from the surface, thermal phenomena are bidimensional hence a 2-D thermal model is used, and beyond a 1-D thermal model is sufficient. $\Gamma_{e}$ is the estimated length where the power is dissipated in surface. Because of the important temperature gradient in the device, specially in the intercellular region, it is necessary to use a fine discretization mesh in this region (as shown in Fig. 11) to obtain accurate results.

The electrons flowing through the base-collector junction generate heat due to their collisions with the crystal structure. The corresponding dissipated power $P_{\text {MOS }}$ is given by

$$
P_{\mathrm{MOS}}=V_{\mathrm{bc}} I_{\mathrm{MOS}}
$$

In the same way the holes flowing through the base-collector depletion layer generate heat by the dissipated power $P_{\mathrm{bc}}$ given by

$$
P_{\mathrm{bc}}=V_{\mathrm{bc}}\left(I_{A}-I_{\mathrm{MOS}}\right)
$$

The equivalent power dissipated in the base resistance and in the emitter-base depletion layer (due to carrier-crystal structure collisions) is given by

$$
P_{p}=V_{\mathrm{eb0}} I_{A}+R_{b} I_{A}^{2}
$$

Where $V_{\text {ebo }}$ is the emitter-base diffusion depletion voltage, and $R_{b}$ is the conductivity-modulated base resistance. The evalu- 


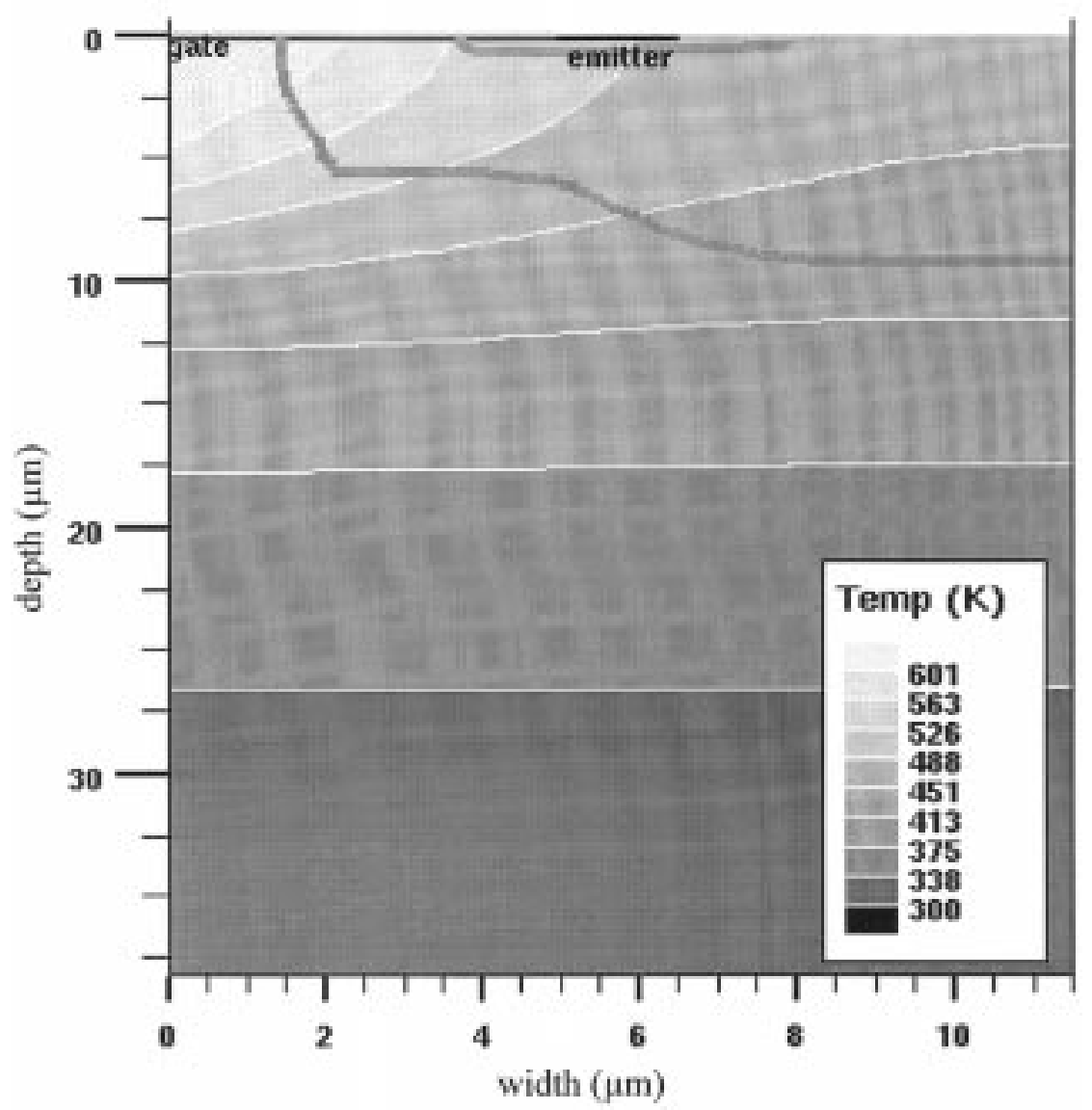

Fig. 8. Temperature distribution in the IGBT half-cell, after $13 \mu$ s short-circuit test, obtained by the ATLAS simulator: $V_{c}=400 \mathrm{~V}$ and $V_{\mathrm{GS}}=16 \mathrm{~V}$.

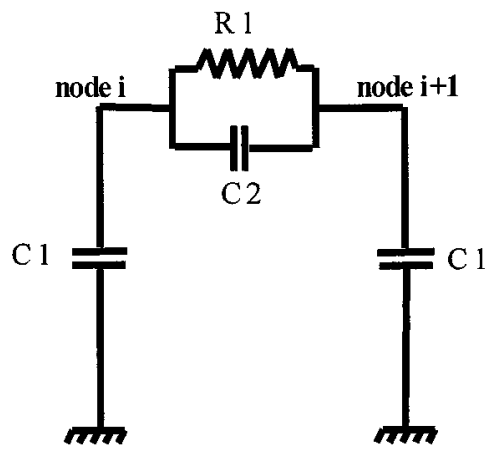

Fig. 9. Unidimensional equivalent thermal networks, between two nodes, obtained by the finite element method.

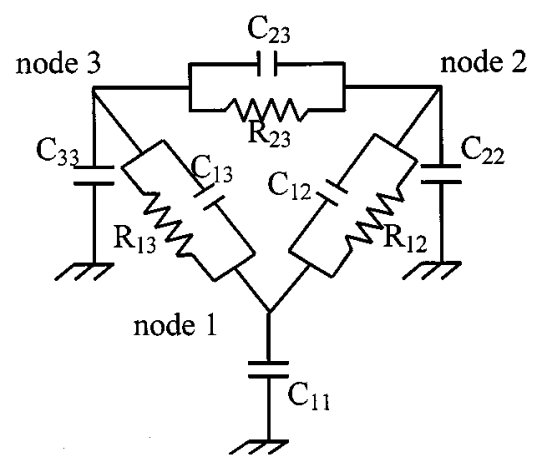

Fig. 10. Bidimensional equivalent networks, for a triangular element, obtained by the finite element method.

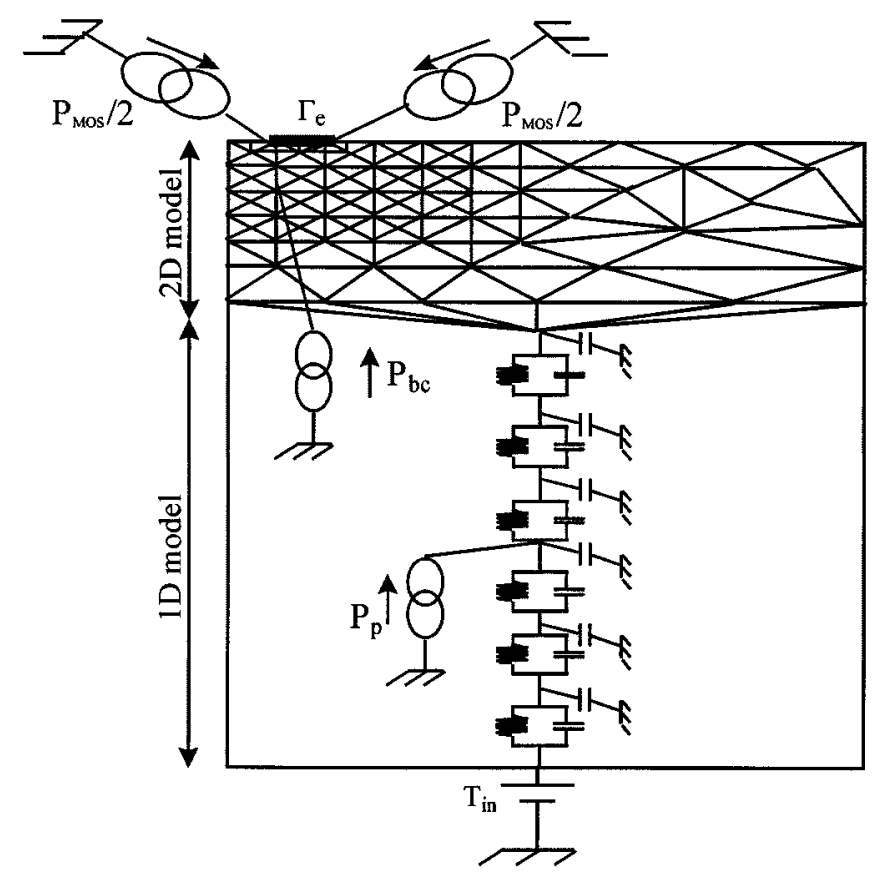

Fig. 11. The proposed thermal model of the IGBT.

ation of the dissipated power by the electrical model is sufficient to predict the temperature in the different regions inside the IGBT. So, in the following study, thermal and electrical models 
are coupled to give an adequate model of the IGBT allowing an accurate description of the electrothermal behavior.

\section{ELECTROTHERMAL MODELING}

\section{A. Temperature Dependency of the Electrical and Physical Parameters}

Physical parameters in the electrical model depend on temperature inside the component. Some of these parameters correspond to a phenomenon in different regions, which have different temperatures, like the mobility.

So, some local temperatures are estimated from the thermal model and then are used in the different physical parameter expressions of the electrical model. For example, the temperature in the MOSFET channel $\left(T_{\mathbf{c h}}\right)$ is needed to evaluate threshold voltage $V_{\text {th }}$ [27] and the surface mobility $\mu_{\text {ns }}$ [27]. Different temperatures in the base-collector depletion region [temperature near the intercellular region $\left(T_{\mathrm{b}-\mathrm{c} 1}\right)$ and the equivalent temperature in the middle of the base-collector depletion region $\left(T_{\mathrm{b}-\mathrm{c} 2}\right)$ ] are used to evaluate thermal generation current (Fig. 8). Temperatures in the base region $\left(T_{b}\right)$ are needed to evaluate conductivity-modulated base resistance, the base high-level lifetime, the mobility and the intrinsic carrier concentration. The temperature in the emitter-base depletion region $\left(T_{\mathrm{b}-\mathrm{e}}\right)$ is used to evaluate the emitter-base diffusion depletion voltage.

It is important to note that in the case of large power surges, and when the device temperature is high, all the physical parameter dependencies are to be taken into account.

For instance, the intrinsic concentration is given by [28]

$$
\begin{aligned}
n_{i}(T)= & 3.87 * 10^{16} \exp \left(-\frac{7.02 * 10^{3} * 1 \mathrm{~K}}{T}\right) \\
& \times(T / 1 \mathrm{~K})^{3 / 2}\left(\mathrm{~cm}^{-3}\right) .
\end{aligned}
$$

The thermal generated leakage current given by the expression (4) is divided on two parts depending on the effective surface corresponding to the intercellular region $\left(A_{\mathrm{gd}}\right)$ and the cellular region $\left(A-A_{\mathrm{gd}}\right)$. These expressions are calculated with the temperatures $T_{\mathrm{b}-\mathrm{c} 1}$ and $T_{\mathrm{b}-\mathrm{c} 2}$ respectively (Appendix 1).
The saturation velocity of electrons and holes are given respectively by

$$
\begin{aligned}
& v_{n \text { sat }}=1.434 * 10^{9}(T / 1 \mathrm{~K})^{-0.87}(\mathrm{~cm} / \mathrm{s}) \\
& v_{p \text { sat }}=1.624 * 10^{8}(T / 1 \mathrm{~K})^{-0.52}(\mathrm{~cm} / \mathrm{s}) .
\end{aligned}
$$

These expressions are valid in low doped regions (in the base for example, $T=T_{b}$ ).

The electrons and hole mobilities are given by Naraind Arora and al [29] following expressions (for $T=T_{\mathrm{ch}}$ ). See (13) and (14) at the bottom of the page. Where $C\left(\mathrm{~cm}^{-3}\right)$ is the doping level concentration ( $p$ or $n$ ) of the considered region.

Electrons and hole lifetime are given by $\left(T=T_{b}\right)$

$$
\tau_{n, p}(T)=\tau_{n, p}(T=300 \mathrm{~K})\left(\frac{T}{300 \mathrm{~K}}\right)^{1.7}(\mathrm{~s}) .
$$

The thermodynamic voltage is given by

$$
U_{T}=\frac{k T}{q} \text {. }
$$

The threshold voltage $V_{\text {th }}$ is given by

$$
V_{\mathrm{th}}=V_{\mathrm{FB}}+2 \psi_{B}+\sqrt{\frac{4 q \varepsilon_{s} N_{A} \psi_{B}}{C_{\mathrm{ox}}}}
$$

where $\psi_{B}$ is the most temperature-dependent parameter given by $\left(T=T_{\mathbf{c h}}\right)$

$$
\psi_{B}=\frac{k T}{q} \ln \left(\frac{N_{A}}{n_{i}(T)}\right) .
$$

The threshold voltage behavior as a function of temperature may be obtained by experimental measurements. This characteristic is approximately linear [27].

The MOSFET current in electrical model is given by [15], [16]. See (19) at the bottom of the page, where $K_{p}$ lin and $K_{p \text { sat }}$ depends on channel temperature $\left(T=T_{\mathbf{c h}}\right)$.

$K_{p \text { lin }}$ parameter is proportional to the electron mobility in the channel, so

$$
K_{p \operatorname{lin}}=K_{p \operatorname{lin} 0} \frac{\mu_{n}(T)}{\mu_{n}(T=300 \mathrm{~K})}
$$

where $K_{p \operatorname{lin} 0}$ is the value of $K_{p \operatorname{lin}}$ evaluated at room temperature $(T=300 \mathrm{~K})$.

$$
\begin{aligned}
& \mu_{n}(T, C)=88(T / 300 \mathrm{~K})^{-0.57}+\frac{7.4 * 10^{8}(T / 1 \mathrm{~K})^{-2.33}}{1+\left[\frac{C}{1.26 * 10^{17}(T / 300 \mathrm{~K})^{2.4}}\right]^{0.88(T / 300 \mathrm{~K})^{-0.146}}\left(\mathrm{~cm}^{2} / \mathrm{V} / \mathrm{s}\right)} \\
& \mu_{p}(T, C)=54.3(T / 300 \mathrm{~K})^{-0.57}+\frac{1.36 * 10^{8}(T / 1 \mathrm{~K})^{-2.33}}{1+\left[\frac{C}{2.35 * 10^{17}(T / 300 \mathrm{~K})^{2.4}}\right]^{0.88(T / 300 \mathrm{~K})^{-0.146}}\left(\mathrm{~cm}^{2} / \mathrm{V} / \mathrm{s}\right)}
\end{aligned}
$$

$$
I_{\mathrm{MOS}}= \begin{cases}0, & \text { for } V_{\mathrm{GS}}<V_{\mathrm{th}} \\ K_{p \operatorname{lin}} \frac{\left(V_{\mathrm{GS}}-V_{\mathrm{th}}\right) V_{\mathrm{DS}}-\frac{K_{p \operatorname{lin}}}{2 K_{p \text { sat }}} V_{\mathrm{DS}}^{2}}{1+\theta\left(V_{\mathrm{GS}}-V_{\mathrm{th}}\right)}, & \text { for } V_{\mathrm{DS}} \leq\left(V_{\mathrm{GS}}-V_{\mathrm{th}}\right) \frac{K_{p \text { sat }}}{K_{p \text { lin }}} \\ K_{p \text { sat }} \frac{\left(V_{\mathrm{GS}}-V_{\mathrm{th}}\right)^{2}}{2\left[1+\theta\left(V_{\mathrm{GS}}-V_{\mathrm{th}}\right)\right]}, & \text { for } V_{\mathrm{DS}}>\left(V_{\mathrm{GS}}-V_{\mathrm{th}}\right) \frac{K_{p \text { sat }}}{K_{p \text { lin }}}\end{cases}
$$




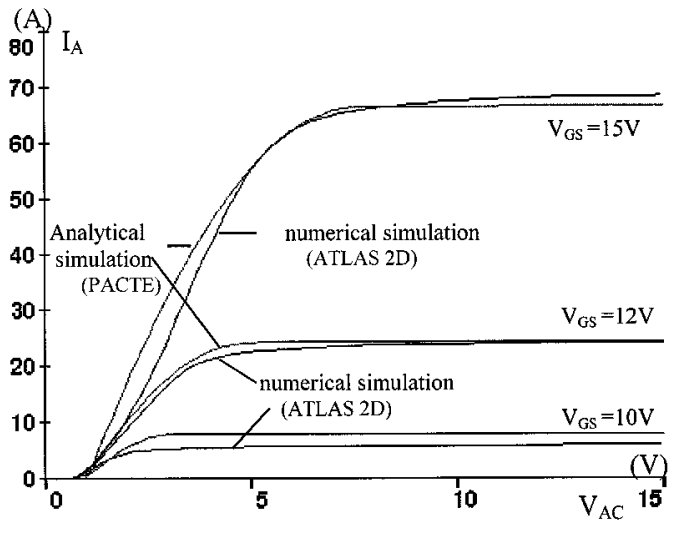

Fig. 12. Static characteristics, of the IGBT device, obtained by the numerical simulator (ATLAS 2-D) and the equivalent analytical model (PACTE).
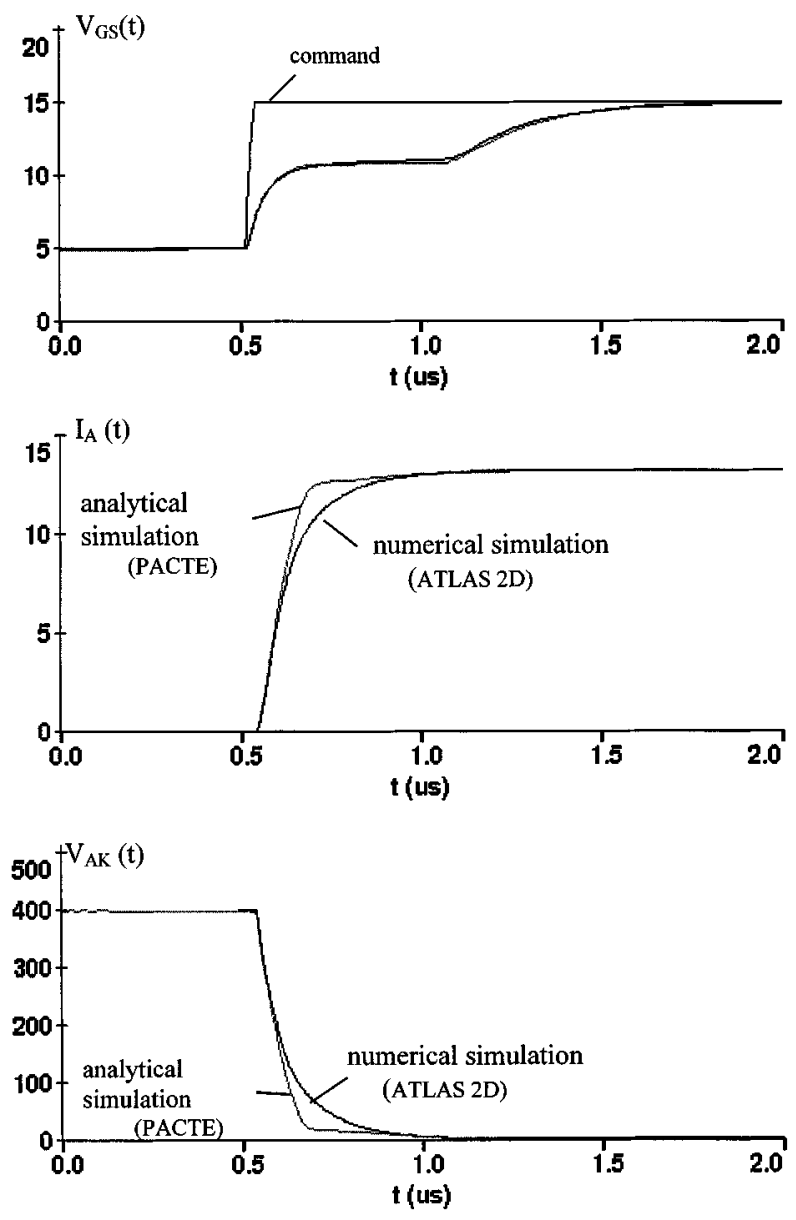

Fig. 13. Current and voltage waveforms obtained for the IGBT device, in the turn-on transient. (Electrical circuit of Fig. 2 with $V_{c}=400 \mathrm{~V}, R_{\mathrm{GS}}=120 \Omega$, $R_{c}=30 \Omega$, and $\left.L_{c}=0.5 \mu \mathrm{H}\right)$.

The ratio $K_{p \operatorname{lin}} / K_{p \text { sat }}$ is supposed to be given by [30]

$$
\frac{K_{p \operatorname{lin}}}{K_{p \text { sat }}}=1+\frac{\sqrt{q \varepsilon_{S} N_{A}}}{2 C_{\mathrm{ox} d}} \frac{1}{\sqrt{\psi_{B}}}
$$

from (20) and (21) we obtain

$$
K_{p \text { sat }}(T)=\frac{K_{p \operatorname{lin}}(T)}{1+\frac{q}{2 C_{\mathrm{oxd} d}} \sqrt{\frac{\varepsilon_{s} N_{A}}{k T \ln \left(\frac{N_{A}}{n_{i}(T)}\right)}}} .
$$
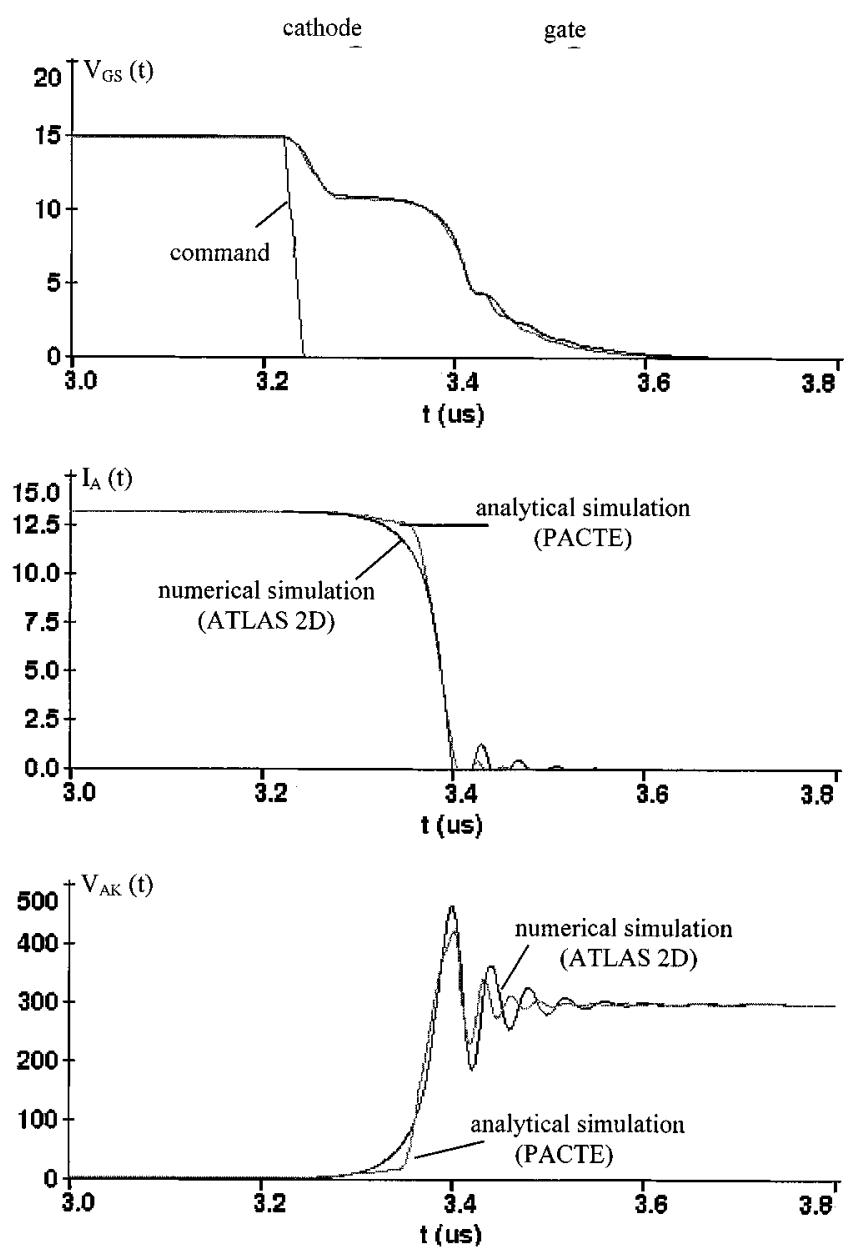

Fig. 14. Current and voltage waveforms obtained for the IGBT device, in the turn-off transient. $\left(V_{c}=300 \mathrm{~V}, R_{G S}=70 \Omega, R_{c}=22.43 \Omega\right.$ and $L_{c}=$ $0.5 \mu \mathrm{H})$.

The internal currents and voltages inside the IGBT are used to calculate the power dissipation in the device. This leads to compute the different region temperatures inside the IGBT by the developed (2-D) thermal model and so to evaluate the corresponding physical parameter values.

To take into account the thermal conductivity variation as function of temperature, the thermal resistance between two nodes is evaluated as a function of an equivalent temperature $\left(T_{\text {moy }}\right)$ given by

$$
T_{\mathrm{moy}}=\frac{T_{i}+T_{j}}{2} \text { between the nodes } i \text { and } j .
$$

In the following sections we perform the comparison between the electrothermal behavior of the IGBT obtained by the analytical model, the numerical simulator and the experiments.

\section{B. Comparison with Numerical Simulation Results}

The complete identification of all the technological parameters of a real structure by numerical simulations demands too much time, probably several hundreds of simulation fitting phases. So we have set arbitrary values to the technological parameters (structure dimensions, doping level, junction depth, oxide thickness...) of half of a symmetric IGBT cell which is 


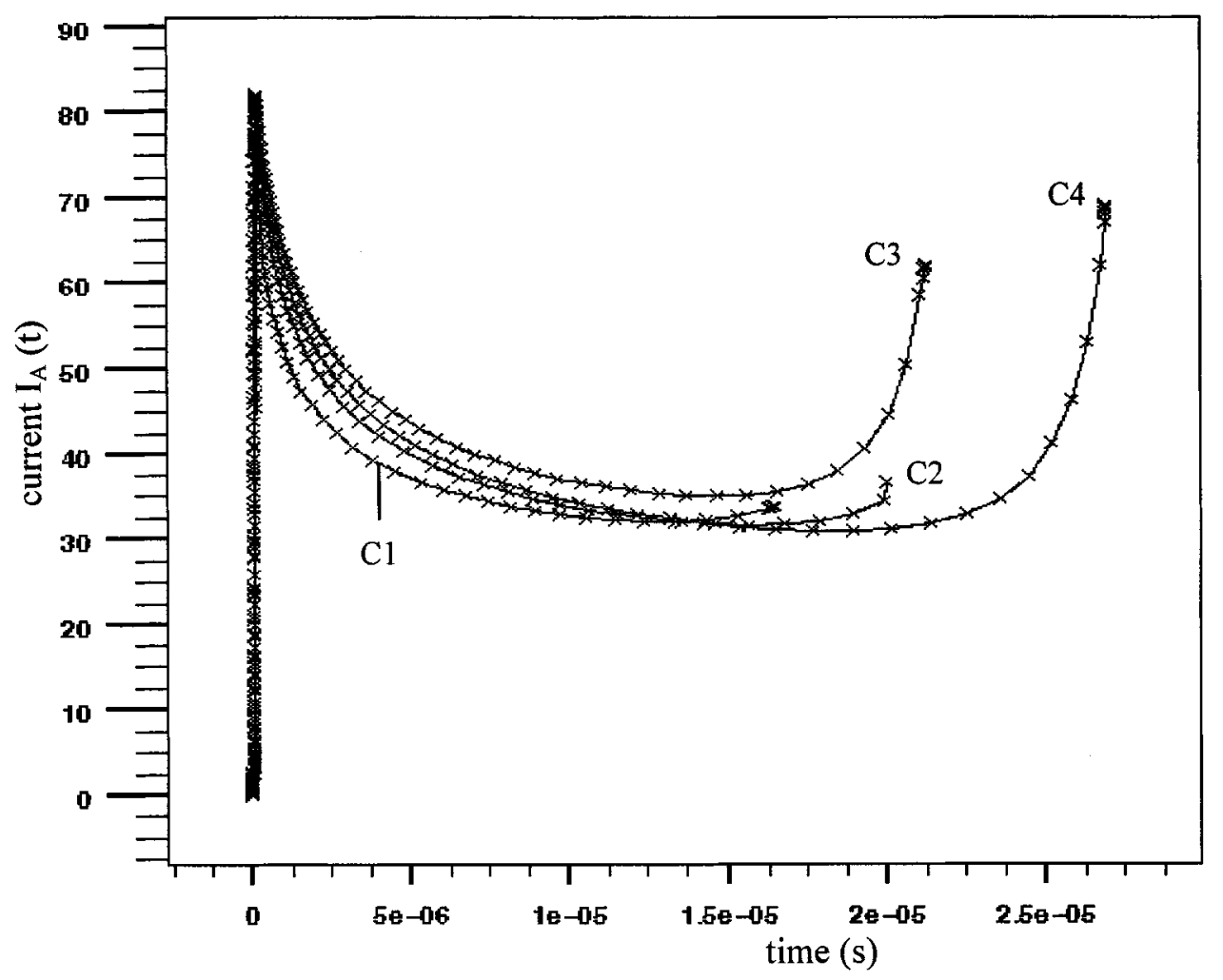

Fig. 15. Short-circuit current evolution of the half of an IGBT cell, for different structure characteristics, obtained with the numerical simulator (ATLAS 2-D). (C1) $\left(N_{L}=3 * 10^{14} \mathrm{~cm}^{-3}, A=0.098 \mathrm{~cm}^{2}\right.$, the intercellular concentration is about $\left.5 * 10^{16} \mathrm{~cm}^{-3}\right)(\mathrm{C} 2)\left(N_{L}=5 * 10^{14} \mathrm{~cm}^{-3}, A=0.10^{7} \mathrm{~cm}^{2}\right.$, the intercellular concentration is about $\left.1 * 10^{16} \mathrm{~cm}^{-3}\right)(\mathrm{C} 3)\left(N_{L}=5 * 10^{14} \mathrm{~cm}^{-3}, A=0.098 \mathrm{~cm}^{2}\right.$, the intercellular concentration is about $\left.2 * 10^{16} \mathrm{~cm}^{-3}\right)(\mathrm{C} 4)$ ( $N_{L}=1.5 * 10^{14} \mathrm{~cm}^{-3}, A=0.10^{7} \mathrm{~cm}^{2}$, the epitaxial layer doping is homogenous).

used as a reference. Indeed, the I-V static characteristics and the transient responses of the proposed structure is closed to those of the device IRGBC 20U. So, we propose to establish the corresponding electrothermal model of this proposed structure. The comparison of the results given by both simulations (numerical model and the analytical model) enable to justify the accuracy of the thermal model mesh (Section II) and the region-temperature dependencies of the physical parameters (Section III-A).

Some electrical characteristics are shown in Figs. 12-14. They picture the comparison between the results obtained by the numerical model (ATLAS 2-D) and the analytical model (PACTE). Fig. 12 shows the I-V characteristic for different gate-to-source voltage values. Fig.s 13 and 14 show the electrical waveforms obtained by both simulations in the case of the turn-on and the turn-off transients of the IGBT, respectively, with the circuit in Fig. 2.

These results show a good agreement between the numerical and the analytical model. Some discrepancies exist between the two simulations specially in the case of the turn-off transients. This is mainly due to the simplifications introduced in the analytical model. However the latter discrepancies have to be put in balance with the significant difference in simulation cost between the numerical model and the analytical model. For instance, the simulation using the numerical simulator (ATLAS) of the turn-off transient (Fig. 14) of half of a symmetric cell structure has required about 8000 minutes of CPU-time on a
SparcStation 10, while the same simulation using the analytical model with the PACTE circuit simulator demands about $15 \mathrm{~s}$ on the same workstation.

The analytical model parameters used in the simulations, and corresponding to the proposed structure (Fig. 7), are given in Appendix 2.

\section{Short-Circuit Conditions}

In the case of large power surge conditions, specially in the case of short-circuit, the IGBT is submitted to a large dissipated power which induces (as mentioned in Section II) high local temperatures throughout the device. So, the device fails very soon if no protection circuit has been implemented.

Fig. 15 shows short-circuit currents in the IGBT, obtained by simulation for different structures when they are submitted to $400 \mathrm{~V}$ between drain and source and $16 \mathrm{~V}$ between gate and source. Two important phases appear in the short-circuit current behavior. First the decrease of the current is mainly due to a decrease of the surface mobility in the MOSFET channel when the channel temperature is rising. Second, an increase of the current inside the device is due to the increase of the thermally generated current $\left(I_{\text {gen }}\right)$. The second phases is critical and the IGBT becomes uncontrollable (the thermal runaway phenomenon establishes rapidly). Fig. 16 shows the electrical and the thermal response behaviors obtained by both the numerical model and 

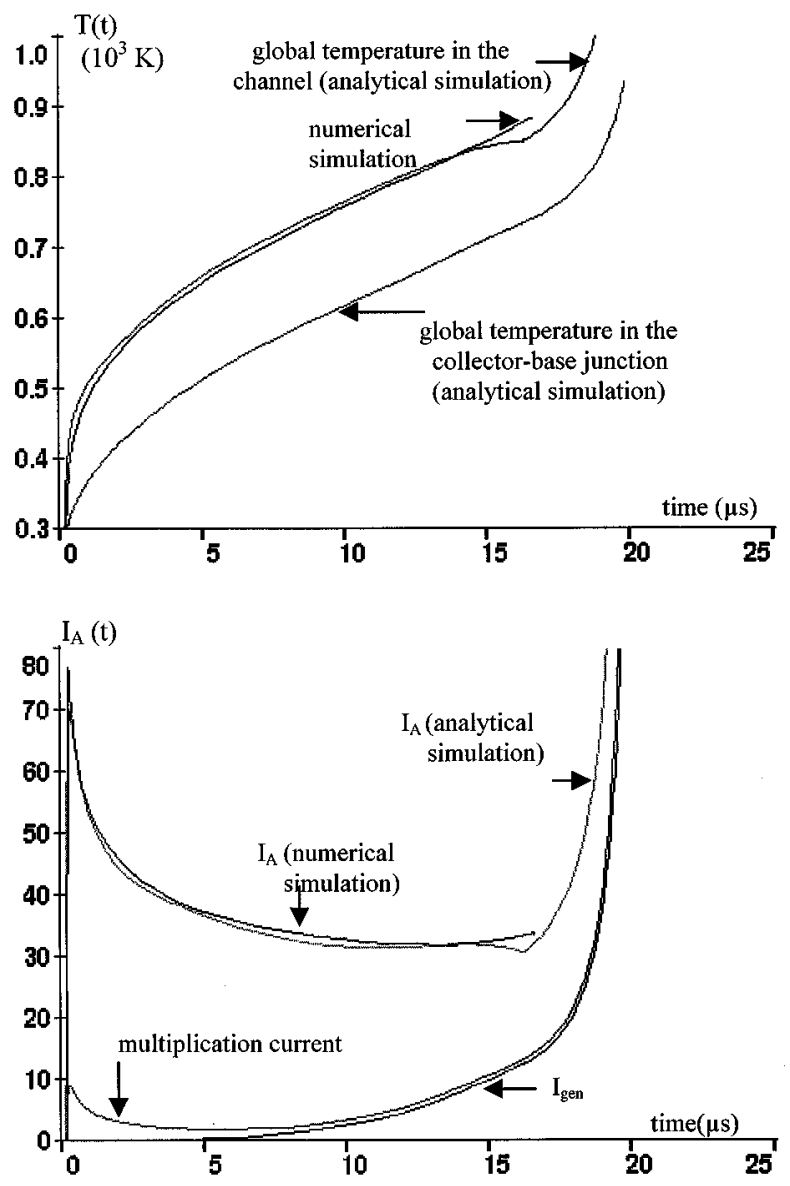

Fig. 16. Short-circuit current and temperature behaviors, in the proposed half of an IGBT cell (C1), obtained with the numerical model (ATLAS 2-D) and the analytical model (PACTE): $V_{c}=400 \mathrm{~V}$ and $V_{\mathrm{GS}}=16 \mathrm{~V}$.

analytical model in the case of short-circuit conditions. The results obtained by both simulations are in good agreement. This demonstrates the practical accuracy of the electrothermal model and the physical parameter-region temperature dependencies as proposed in here-above sections.

The maximum temperature reached inside the device (when the short-circuit current runway begins) is about $900 \mathrm{~K}$ what corresponds to the intrinsic temperature in the $P / P^{+}$doping region. These observations confirm the experimental results given in [27].

Fig. 17 shows the comparison between the experimental and simulated results obtained for the IRGBC $20 \mathrm{U}$ device in the case of a destructive short-circuit. The measured evolutions show that the estimation of the IGBT failure phenomenon by mean of simulation, in the case of large power surge conditions, is highly possible and largely reliable in the presented case. However the accuracy of the proposed electrothermal model of the IGBT is tributary of the accuracy of the physical parameter-temperature dependencies established in this section. Unfortunately, some of these parameter dependencies remain unknown when the local temperature exceeds $600 \mathrm{~K}$. This may explain the discrepancies on critical phase behaviors obtained by the experimental test and by the analytical model.
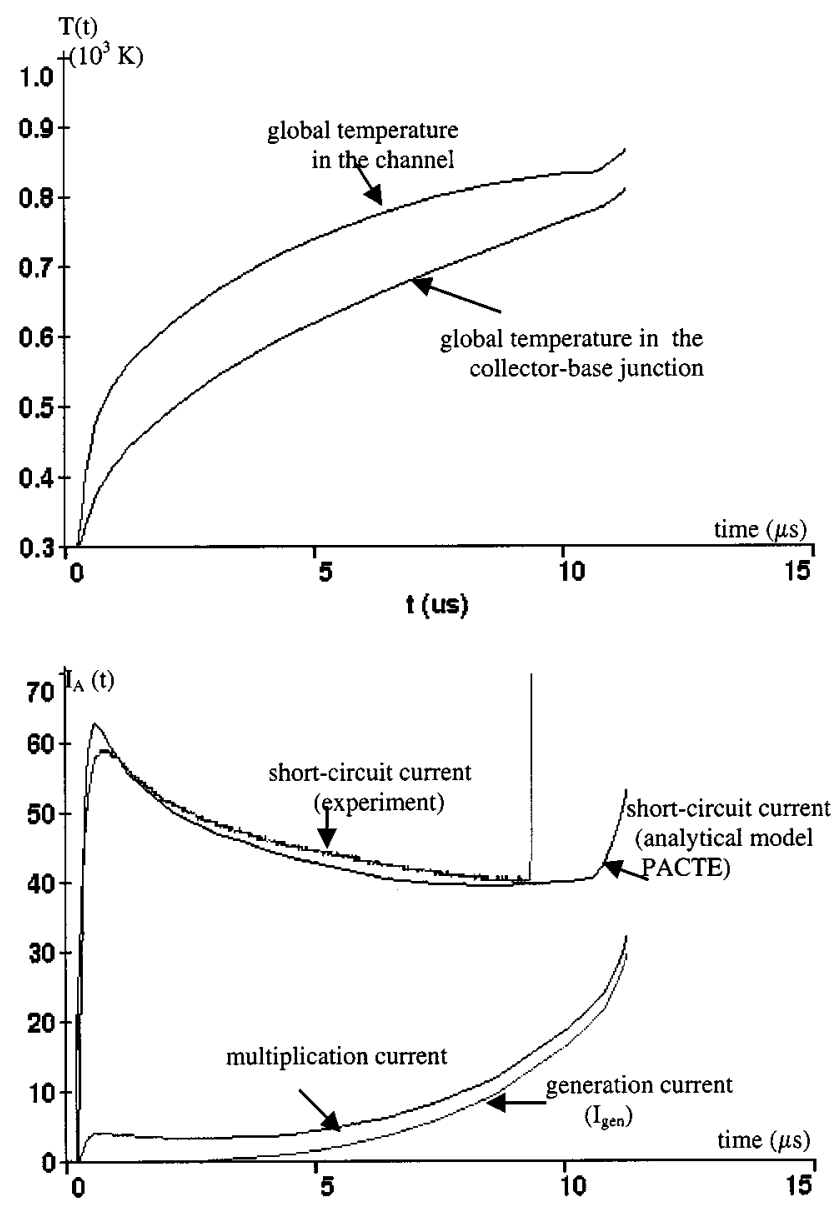

Fig. 17. Experimental and simulated (analytical model) behavior of the currents and the temperature in the IRGBC $20 \mathrm{U}$ under short-circuit conditions: $V_{c}=400 \mathrm{~V}$ and $V_{\mathrm{GSS}}=15 \mathrm{~V}$.

\section{CONCLUSION}

Both analytical and numerical electrothermal models of the IGBT under short-circuit, have been developed. The analytical model is based on an electrical model (Hefner model) coupled with a 2-D thermal model. The numerical model has been simulated using the ATLAS-2-D simulator and so far is used as a reference. The obtained results are in good agreement with measurements in the case of large power surge conditions, except when high temperatures are reached inside the device. This is due to the fact that some temperature dependency expressions of physical parameters, e.g., mobilities, are not known when the temperature is higher than $600 \mathrm{~K}$.

The numerical model is accurate but demands a precise knowledge of all the technological parameters of the device structure. Moreover the simulation cost is very expensive (several day of CPU time), so it is not possible to obtain good parameter value fittings with measurements. However it is remarkable that such a numerical model is very easy to develop (about one day of work) using a simulator like ATLAS-2-D.

Beside the analytical model has demanded a large effort to be developed (several months), but it gives acceptable accuracy with a very short simulation cost ( $\sim 15 \mathrm{~s})$. So using such a model, measurement fitting is possible. 
Hence, we have shown that analytical model may enable to predict the short-circuit behavior of IGBT's in circuit simulator. This would be applied to the design of short-circuit protection circuits or to the simulation of circuit reliability.

\section{APPENDIX 1}

Expressions of the Punch-through IGBT electrical model:

$$
\begin{aligned}
& N_{\mathrm{sc}}=N_{L}+N_{\mathrm{sat}} \\
& W_{\mathrm{eff}}^{2}=\sqrt{W^{2}+W_{H}^{2} \frac{D_{c}}{D_{p H}}+\frac{W_{H}^{2}}{2 D_{p H}} \frac{W C_{\mathrm{bc} j}}{3 q A N_{L}} \frac{d V_{\mathrm{bc}}}{d t}} \\
& W_{\mathrm{gd} j}=\sqrt{\frac{2 \varepsilon_{\mathrm{si}}\left(V_{\mathrm{dg}}+V_{T d}\right)}{q N_{\mathrm{sc}}}} \\
& W_{\mathrm{ds} j}=\sqrt{\frac{2 \varepsilon_{\mathrm{si}}\left(V_{\mathrm{ds}}+V_{\mathrm{bi}}^{\mathrm{ds}}\right)}{q N_{\mathrm{sc}}}} \\
& W_{\mathrm{bc} j}=\sqrt{\frac{2 \varepsilon_{\mathrm{si}}}{q N_{\mathrm{sc}}} V_{\mathrm{bc}}} \\
& W=W_{L}-W_{\mathrm{bc} j} \\
& C_{\mathrm{bc} j}=\frac{A \varepsilon_{\mathrm{si}}}{W_{\mathrm{bc} j}} \\
& C_{\mathrm{ds} j}=\frac{\left(A-A_{\mathrm{gd}}\right) \varepsilon_{\mathrm{si}}}{W_{\mathrm{ds} j}} \\
& C_{\mathrm{gd} j}=\frac{A_{\mathrm{gd}} \varepsilon_{\mathrm{si}}}{W_{\mathrm{gd} j}} \\
& C_{\mathrm{ce}}=\frac{W^{2}}{W_{\mathrm{eff}}^{2}} \frac{C_{\mathrm{bc} j} Q_{T}}{3 q A W N_{\mathrm{sc}}} \\
& C_{\mathrm{gd}}= \begin{cases}C_{\mathrm{ox}}, & \text { for } V_{\mathrm{ds}} \leq V_{\mathrm{GS}}-V_{T d} \\
\frac{C_{\mathrm{ox}} C_{\mathrm{gd} j}}{C_{\mathrm{ox}}+C_{\mathrm{gd} j}}, & \text { for } V_{\mathrm{ds}}>V_{\mathrm{GS}}-V_{T d}\end{cases} \\
& Q_{H}=Q_{T}-Q_{L} \\
& 1 / \mu_{c}=\left[\Delta p \operatorname{Ln}\left(1+\alpha_{2}(\Delta p)^{-2 / 3}\right)\right] / \alpha_{1} \\
& \mu_{n c}=1 /\left(1 / \mu_{n}\left(T_{b}\right)+1 / \mu_{c}\left(T_{b}\right)\right) \\
& \mu_{p c}=1 /\left(1 / \mu_{p}\left(T_{b}\right)+1 / \mu_{c}\left(T_{b}\right)\right) \\
& D_{c}=2 U_{T}\left(T_{b}\right) \frac{\mu_{n c} \mu_{p c}}{\mu_{n c}+\mu_{p c}} \\
& L=\sqrt{\tau_{L}\left(T_{b}\right) D_{c}} \\
& P_{L 0}=\frac{Q_{L}}{q A L} \frac{\sinh (W / L)}{\cosh (W / L)-1} \\
& P_{H 0}=\frac{2 Q_{H}}{q A W_{H}}-P_{L 0}\left(P_{L 0}+N_{L}\right) / N_{H} \\
& n_{\mathrm{eff}} \approx \frac{\frac{W}{2 L} \sqrt{N_{L}^{2}+P_{L 0}^{2} \cosh ^{2}(W / L)}}{\operatorname{arctgh}\left[\frac{\sqrt{N_{L}^{2}+P_{L 0}^{2} \cosh ^{2}(W / L)}}{N_{L}+P_{L 0} \cosh (W / 2 L)}\right]}
\end{aligned}
$$

$$
\begin{aligned}
& R_{b} \approx \frac{W}{(1+1 / b) \mu_{n}\left(T_{b}\right) A q n_{\mathrm{eff}}} \\
& V_{\mathrm{ebd}}=V_{\mathrm{eb} 0}\left(T_{\mathrm{b}-\mathrm{e}}\right)-U_{T}\left(T_{\mathrm{b}-\mathrm{e}}\right) \frac{\left(D_{p}-D_{n}\right)}{\left(D_{p}+D_{n}\right)} \operatorname{Ln}\left(\frac{P_{L 0}+N_{L}}{N_{L}}\right) \\
& V_{\mathrm{eb}}=R_{b} I_{T}+V_{\mathrm{ebd}} \\
& V_{\mathrm{Bcb} 0} \approx 5.3410^{13} N_{L}^{-3 / 4} \\
& W_{m}=\sqrt{\frac{2 V_{\mathrm{Bcb0} \varepsilon_{\mathrm{si}}}}{q N_{L}}} \\
& V_{P T}= \begin{cases}V_{\mathrm{Bcb0}}\left(\frac{W_{L}}{W_{m}}\right)\left(2-\frac{W_{L}}{W_{m}}\right) & \text { if } W_{m}>W_{L} \\
V_{\mathrm{Bcbo}} & \text { if } W_{m}<W_{L}\end{cases} \\
& M=\frac{1}{1-\left(\frac{V_{b c}}{f V_{P T}}\right)^{n}} \\
& I_{c \text { ss }}=\frac{W^{2}}{W_{\mathrm{eff}}^{2}} \frac{1}{1+b} I_{T}+\frac{D_{c} Q_{T}}{W_{\mathrm{eff}}^{2}} \\
& I_{c}=I_{c \mathrm{ss}}+C_{\mathrm{ce}} \frac{d V_{\mathrm{bc}}}{d t} \\
& I_{b \mathrm{ss}}=\frac{Q_{L}}{\tau_{L}\left(T_{b}\right)}+\frac{Q_{H}}{\tau_{H}\left(T_{b}\right)}+\frac{P_{H 0} N_{H}}{n_{i}^{2}\left(T_{b}\right)} I_{\text {sne }}
\end{aligned}
$$

See the equation at the bottom of the page.

$$
\begin{aligned}
& I_{\mathrm{gen}}=\frac{q A_{\mathrm{gd}} n_{i}\left(T_{\mathrm{b}-\mathrm{c} 1}\right)}{\tau_{\mathrm{sc}}\left(T_{\mathrm{b}-\mathrm{c} 1}\right)} W_{\mathrm{bc} j}+\frac{q\left(A-A_{\mathrm{gd}}\right) n_{i}\left(T_{\mathrm{b}-\mathrm{c} 2}\right)}{\tau_{\mathrm{sc}}\left(T_{\mathrm{b}-\mathrm{c} 2}\right)} W_{\mathrm{bc} j} \\
& I_{\text {mult }}=(M-1)\left(I_{c s s}+I_{\mathrm{MOS}}\right)+M I_{\mathrm{gen}} \\
& \dot{V}_{\mathrm{ds}}=\frac{I_{c \mathrm{ds}}}{C_{\mathrm{ds} j}} \\
& \dot{V}_{\mathrm{GS}}=\frac{I_{c \mathrm{gs}}}{C_{\mathrm{gs}}} \\
& \dot{Q}_{T}=I_{T}-I_{c \mathrm{ce}}-I_{b \mathrm{ss}}-I_{c \mathrm{ss}} \\
& V_{\mathrm{ds}}+V_{\mathrm{eb}}=V_{\mathrm{ec}} \\
& \Delta p=P_{L 0} \frac{\sinh [W / 2 L]}{\sinh [W / L]} \\
& N_{\text {sat }}=I_{c} /\left(q A v_{p \text { sat }}\left(T_{\mathrm{b}-\mathrm{c} 2}\right)\right)-I_{\mathrm{MOS}} /\left(q A v_{n \text { sat }}\left(T_{\mathrm{b}-\mathrm{c} 2}\right)\right) \\
& \frac{8 D_{p H}}{W_{H} N_{H}} \frac{1}{q A W^{2}} Q_{L}^{2}+\left(\frac{2 D_{p}}{W^{2}}+\frac{1}{3 W} \frac{d W}{d t}+\frac{2 D_{p H}}{W_{H}^{2}}\right) Q_{L} \\
& =\frac{2 D_{p H}}{W_{H}} Q_{T}-\frac{1}{I+b} I_{T}
\end{aligned}
$$

APPENDIX 2

See Table I.

$$
I_{\mathrm{MOS}}= \begin{cases}0, & \text { for } V_{\mathrm{GS}}<V_{T} \\ K_{p \operatorname{lin}}\left(T_{\mathrm{ch}}\right) \frac{\left(V_{\mathrm{GS}}-V_{T}\left(T_{\mathrm{ch}}\right)\right) V_{\mathrm{DS}}-\frac{K_{p \operatorname{lin}}\left(T_{\mathrm{cl}}\right)}{2 K_{p \mathrm{sat}}\left(T_{\mathrm{cl}}\right)} V_{\mathrm{DS}}^{2}}{1+\theta\left(V_{\mathrm{GS}}-V_{T}\right)}, & \text { for } V_{\mathrm{DS}} \leq\left(V_{\mathrm{GS}}-V_{T}\right) \frac{K_{p \text { sat }}}{K_{p \text { lin }}} \\ K_{p \mathrm{sat}}\left(T_{\mathrm{ch}}\right) \frac{\left(V_{\mathrm{GS}}-V_{T}\left(T_{\mathrm{ch}}\right)\right)^{2}}{2\left[1+\theta\left(V_{\mathrm{GS}}-V_{T}\left(T_{\mathrm{ch}}\right)\right)\right]}, & \text { for } V_{\mathrm{DS}}>\left(V_{\mathrm{GS}}-V_{T}\right) \frac{K_{p \text { sat }}}{K_{p \operatorname{lin}}}\end{cases}
$$


TABLE I

Electrical Model Parameter VAlues (At RoOM TEMPERATURE) OF THE DifFERENT DEVICES AdDRESSED IN THIS PAPER

\begin{tabular}{|c|c|c|c|c|c|c|c|c|c|c|c|c|c|c|c|c|}
\hline 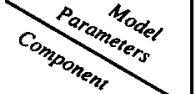 & $\underset{\left(\mathrm{cm}^{2}\right)}{A}$ & $\begin{array}{c}A_{g^{d}} \\
\left(\mathrm{~cm}^{2}\right)\end{array}$ & $\begin{array}{c}W_{L} \\
(\mu m)\end{array}$ & $\underset{(\mu m)}{W_{H}}$ & $\begin{array}{l}V_{\text {th }} \\
(V)\end{array}$ & $\begin{array}{l}V_{t d} \\
(V)\end{array}$ & $\begin{array}{c}K_{\text {plino }} \\
\left(A W^{2}\right)\end{array}$ & $\begin{array}{c}K_{p s a t o} \\
\left(A N^{2}\right)\end{array}$ & $\begin{array}{c}C_{g s} \\
(n F)\end{array}$ & $\begin{array}{c}C_{o x} \\
(n F)\end{array}$ & $\begin{array}{l}N_{L} \\
\left(\mathrm{~cm}^{-3}\right)\end{array}$ & $\begin{array}{l}N_{H} \\
(\mathrm{~cm} \cdot \mathrm{s})\end{array}$ & $\begin{array}{l}\tau_{L} \\
(\mu s)\end{array}$ & $\begin{array}{l}\tau_{H} \\
(\mu s)\end{array}$ & $\begin{array}{r}1 / \theta \\
(V)\end{array}$ & $\begin{array}{l}\text { Isne } \\
\left(10^{-14} A\right)\end{array}$ \\
\hline$I R G B C 20 U$ & 0.11 & 0.033 & 58 & 14.5 & 4.5 & -4.5 & I.I & 0.9 & 0.24 & 0.4 & $1.3 * 1014$ & $2 * 10^{17}$ & 0.25 & 0.1 & 70 & 8 \\
\hline $\begin{array}{l}\text { corresponding to the } \\
\text { one half IGBT cell } \\
\text { used in the numerical } \\
\text { simulation (ATLAS) }\end{array}$ & 0.1 & 0.025 & 48 & 13.5 & 6.5 & -6.5 & 2.2 & 1.8 & 0.79 & 0.76 & $2.5 * 10^{14}$ & $2 * 10^{17}$ & 0.15 & 0.1 & 70 & 5 \\
\hline BUP 202 & 0.1 & 0.05 & 200 & & 5 & -0.1 & 1.9 & 1.0 & 0.58 & 1.9 & 0.25 & & & 1 & 70 & 20 \\
\hline
\end{tabular}

\section{REFERENCES}

[1] F. F. Protiwa, O. Apeldoorn, and N. Gross, "New IGBT model for PSPICE," in Proc. EPE'93, Sept. 1993, pp. 226-231.

[2] R. Kraus, P. Turkes, and H. J. Mattausch, "Modeling the self-heating of power devices," in Proc. Int. Symp. Power Semicon. Devices IC's, Tokyo, Japan, 1992, pp. 124-129.

[3] A. R. Hefner and D. L. Blakburn, "Thermal component models for electrothermal network simulation," IEEE Trans. Comp., Packag., Manufact. Technol. A, vol. 17, pp. 413-424, Sept. 1994.

[4] B. Fatemizadeh, D. Silber, M. Fullmann, and J. Serafin, "Modeling of LDMOS and LIGBT structures at high temperatures," in Proc. 6th Int. Symp. Power Semicon. Devices IC's, Davos, Switzerland, May/June 1994, pp. 137-142.

[5] P. Turkes, W. Kiffe, and R. Kuhnert, "Critical switching conditions of a nonpunch-through IGBT investigated by electrothermal circuit simulation," in Proc. 6th Int. Symp. Power Semicon. Devices IC's, Davos, Switzerland, May 31, June 2 1994, pp. 51-55.

[6] A. Amimi, R. Bouchakour, and T. Maurel, "Modeling and simulation of self-heating and/or degradation effects for the IGBT transistor," in Proc. PESA'96 Symp. Modeling, Anal., Simulation, Lille, France, July 9-12, pp. 855-860.

[7] A. Ammous, S. Ghedira, B. Allard, and H. Morel, "Choosing thermal model for electrothermal simulation," IEEE Trans. Power Electron., vol 14, pp. 300-307, Mar. 1999.

[8] H. Hiroyasu, J. Yamachita, A. Uenishi, and H. Haruguchi, "An experimental and numerical study on the forward biased SOA of IGBT's," IEEE Trans. Electron Devices, vol. 43, pp. 490-500, Mar. 1996.

[9] V. Axelrad and R. Klein, "Electrothermal simulation of an IGBT," in Proc. 1992 Int. Symp. Power Semicon. Devices IC's, Tokyo, Japan, pp. $158-169$.

[10] Z. R. Hu, P. A. Mawby, K. Board, and J. Zeng, "Degradation in on-state characteristics of IGBT's through self-heating," Inst. Electron. Eng. Proc.-Circuits Devices Syst., vol. 141, no. 6, pp. 439-444, Dec. 1994.

[11] B. Allard, H. Morel, S. Ghedira, and A. Ammous, "A bond graph simulator for power train simulation including semiconductor device models," in Proc. IEEE, IMACS'96, Lille, France, 1996, pp. 500-505.

[12] Analogy, Inc., "SABER User's Guide, Optional Template Library (Part 2)," Beaverton, OR, Analogy, Aug. 1993.

[13] "HDL-A User's Manual," ANACAD Electrical Engineering Software, France, ELDO, July 1994.

[14] Dolphin Integration, Inc., “ABCD Language Reference Manual,” Dolphin Integration, 38242 Meylan Cedex, France, SMASH ${ }^{\mathrm{TM}}$, Apr. 1996.

[15] A. R. Hefner, Jr., "Modeling buffer layer IGBT's for circuit simulation," in Proc. IEEE PESC'93, Seattle, WA, June 1993, pp. 60-70.

[16] A. R. Hefner Jr. and D. M. Diebolt, "An Experimentally verified IGBT model implemented in the Saber circuit simulator," IEEE Trans. Power Electron., vol. 9, pp. 532-542, Sept. 1994.

[17] Silvaco, Inc., "ATLAS: 2-D Device Simulation Framework," SILVACO INTERNATIONAL, Santa Clara, CA, Apr. 1997.

[18] A. Blicher, Field-Effect and Bipolar Power Transistor Physics. New York: Academic, 1981, p. 312.

[19] B. J. Baliga, Modern Power Devices. New York: Wiley, 1987, p. 476

[20] A. R. Hefner Jr. and D. L. Blackburn, "An analytical model for the steady-state and transient characteristics of power insulated-gate bipolar transistor," Solid-State Electron., vol. 31, no. 10, pp. 1513-1532, 1988
[21] A. R. Hefner Jr., "An improved understanding for the transient operation of the power insulated gate bipolar transistor (IGBT)," IEEE Trans. Power Electron., vol. 5, pp. 459-468, July 1990.

[22] —, "An investigation of the drive circuit requirements for the power insulated gate bipolar transistor (IGBT)," IEEE Trans. Power Electron. vol. 6, pp. 208-219, Mar. 1991

[23] _ "Analytical modeling of device-circuit interactions for the power insulated gate bipolar transistor (IGBT)," IEEE Trans. Ind. Applicat., vol. 26, pp. 995-1005, Dec. 1990.

[24] K. Kato, "IGBT dynamic tester," in Proc. PCIM INTER'98 Jpn., pp. $143-148$.

[25] P. R. Strickland, "The thermal equivalent circuit of a transistor," IBM J., pp. 35-45, 1959.

[26] J. T. Hsu and L. Vu-Quoc, "A rational formulation of thermal circuit models for electrothermal simulation-Part I: Finite element method," IEEE Trans. Circuits Syst., vol. 43, pp. 721-732, Sept. 1996.

[27] A. Ammous, B. Allard, and H. Morel, "Transient temperature measurements and modeling of IGBT's under short-circuit," IEEE Trans. Power Electron., vol. 13, pp. 12-25, Jan. 1998.

[28] S. M. Sze, Physics of Semiconductor Devices, 2nd ed. New York: Wiley, 1981, p. 868.

[29] N. D. Arora, J. R. Hauser, and D. J. Roulston, "Electron and hole mobilities in silicon as a function of concentration and temperature," IEEE Trans. Electron Devices, vol. ED-29, pp. 292-295, Feb. 1982.

[30] J. D. Chatelain, Dispositifs à semiconducteur. Paris, France: Imprimerie Gautier-Villars, 1985, p. 321.

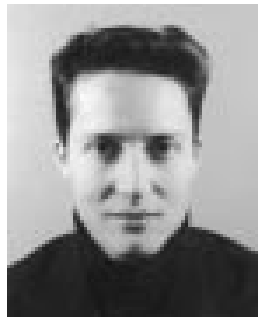

Anis Ammous was born in Sfax, Tunisia, in 1970 He received the electrical engineering degree from the Ecole National d'Ingenieur de Sfax (ENIS), in 1994, and the Ph.D. degree in electrical engineering from the Institut National des Sciences Appliquées (INSA), Lyon, France, in 1998.

In 1999, he joined the ENIS, where he is an Assistant Professor. His current research interests are power semiconductor device modeling, the electrothermal modelization and power electronic applications to electrical vehicles.

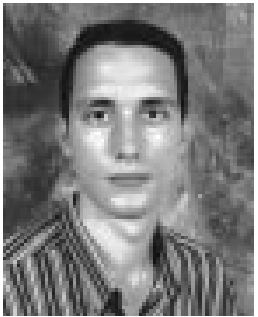

Kaiçar Ammous was born in Sfax, Tunisia, in 1975. $\mathrm{He}$ received the electrical engineering degree from the Ecole Nationale d'Ingénieurs de Sfax (ENIS), in 1997 and is currently pursuing the Ph.D. degree in electrical engineering at the Institut National des Sciences Appliquées (INSA), Lyon, France.

His current research interests are averaged modeling of power converter, and the analysis of measurement errors in estimation of power switching losses based on electrical measurements. 


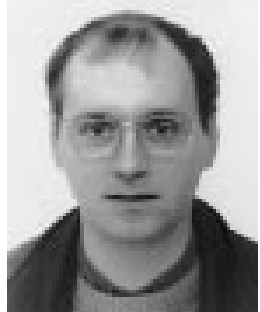

Hervé Morel was born in Reims, France, in 1959. $\mathrm{He}$ received the engineer and Ph.D. degrees from the Ecole Centrale de Lyon, France, in 1982 and 1985, respectively.

He is currently a Researcher at the Centre National de la Recherche Scientifique (CNRS), Centre de Génie Electrique de Lyon (CEGELY), France. He teaches basic electrical engineering. He manages the research team on "power semiconductor devices for power electronics." His research interests are, semiconductor device characterizations and modeling, converter simulations, and designs. A special interest exists for the modeling based on bond graphs.

Dr. Morel is member of the Society for Computer Simulation.

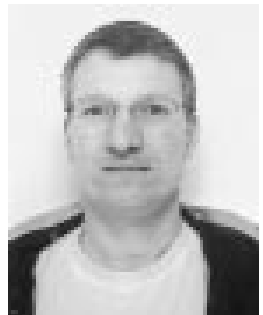

Bruno Allard (M'92) was born in Carignan, France, in 1965. He received the electrical engineering, M.Sc., and Ph.D. degrees from the Institut National des Sciences Appliquées (INSA), Lyon, France, in 1988, 1989, and 1992, respectively.

Since 1991, he has been with the Centre de Génie Electrique de Lyon (CEGELY), France. He is an Assistant Professor at the Electrical Engineering Department, INSA. His present research interests include power semiconductor device modeling and power electronic system simulation, both based on the bond graph approach. In particular, he works on electro-thermal modeling and (integrated) system design.

Dr. Allard is a Member of the European Power Electronic Society and the European Working Group of the IEEE Industrial Application Society.

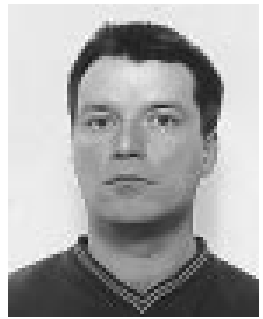

Dominique Bergogne was born in Marvejols, France, in 1966. He received the Ph.D. degree in power electronics from the Blaise Pascal University, Clermond-Ferrand, France in 1992.

$\mathrm{He}$ is currently an Associate Professor in electronics at the IUT Institute, Saint-Etienne, France, where he teaches practical electronics. He is with the Centre de Génie Electrique de Lyon (CEGELY) in the power device team. His research interest is dynamic electrothermal issues and power converter. $\mathrm{He}$ is implied in industrial partnerships.
Fayçal Sellami was born in Sfax, Tunisia, in 1956. He received the electrical engineering degree from the Faculté de Sciences et Techniques, Sfax, Tunisia, in 1981, the "Docteur Ingénieur" (Ph.D.) degree and the "Doctorat d'Etat" degree in electrical engineering from the Institut National Polytechnique de Toulouse (INPT), France, in 1983 and 1986, respectively.

He is currently a Professor at the Ecole Nationale d'Ingénieurs de Sfax (ENIS), Sfax, Tunisia. His research interest is power electronics and he is the responsible of the Power Electronic Laboratory (LEP) and the electric vehicle project at the ENIS.

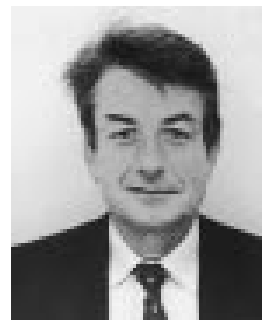

Jean Pierre Chante $\left(\mathrm{M}^{\prime} 81\right)$ was born in Lyon, France, in 1942. He received the "Doctorat d'Etat" degree from the University of Lyon, in 1981.

From 1980 to 1986, he managed a research team in the field of power semiconductor devices at the Ecole Centrale de Lyon. Since 1986, he has been a Professor of Electronic Components and Applied Electronics at the Institut National des Sciences Appliquées (INSA), Lyon, where he is the head of the Power Devices and Applications team which is part of the CEGELY. He is also in charge of the Centre Inter-Universitaire de Microélectronique de la Région de Lyon, which is a regional research center in the microelectronic field. His interests are in high-temperature electronics, SiC-base components, advanced power devices, and $\mathrm{CAD}$ tools for power electronics. 